\title{
Guided Bone Ridge Augmentation: A Clinicohistologic and Radiographic 2 Years Follow-up
}

\author{
Sangeeta Dhir, Lanka Mahesh
}

\begin{abstract}
Background: Augmentation of the bone is done to create the sufficient bone volume for ideal implant placement. This case report presents the effective augmentation of the socket using corticocancellous graft and AlloDerm.
\end{abstract}

Methods: Failing 47 was extracted. Socket had a severe buccal dehiscence extending and a thin keratinized mucosa around. After through debridement, socket walls were decorticated and corticocancellous graft and allograft GBR was tacked over the socket. Mucoperiosteal flap was sutured with 5-0 nylon sutures (Ethicon) Bone core biopsy was done for histologic assessment and site was restored with screw-retained implant prosthesis.

Results: Histologic assessment revealed ingrowth of new bone around the bone graft. Stable soft and hard tissue results have been seen with 2 years follow-up of the case.

Conclusion: Results indicated that ridge preservation using corticocancellous graft and AlloDerm prevented the ridge resorption and helped in enhancement of bone fill and soft tissue volume.

Keywords: Guided bone regeneration, GBR, Ridge augmentation, Alloderm, Socket augmentation, Perio-endo.

How to cite this article: Dhir S, Mahesh L. Guided Bone Ridge Augmentation: A Clinicohistologic and Radiographic 2 Years Follow-up. Int J Oral Implantol Clin Res 2013;4(3):118-121.

Source of support: Nil

Conflict of interest: None declared

\section{INTRODUCTION}

Resorption of the residual alveolar ridge is an inadvertant process after extraction. Chen ${ }^{1}$ and Schropp ${ }^{2}$ have reported an average 0.34 to $7.7 \mathrm{~mm}$ horizontal and 0.2 to $3.25 \mathrm{~mm}$ vertical bone loss 6 months after extraction. Resorbed bone presents difficulty in placement of implant and planning of the future prosthesis. To reduce these difficulties ridge bone maintenance procedures using biomaterials were utilized to preserve the ridge anatomy and increase the possibility of rehabilitation after tooth extraction. The case report aims at evaluating the efficacy of alveolar ridge preservation technique.

\section{CASE REPORT}

Patient presented with pain in lower right region of the mouth. Intraoral examination showed 47 sensitive to percussion with deep periodontal pocket. Radiographic evaluation revealed a fractured 46 (Figs 1 to 3). Treatment planned for the case included : extraction of the tooth, socket augmentation, a delayed placement of the implant-retained prosthesis. After administering local anesthesia, failing 47 was extracted. Thorough debridement of the socket was done to remove the diseased granulation tissue (Fig. 4). A wide buccal dehiscence was present. Horizontal bone width was measured with bone caliper after tooth extraction with reference to the centerpoint of the buccal defect as $5.7 \mathrm{~mm}$. Socket walls were decorticated to infuse the fresh bleeding. Corticocancellous graft MinerOss (Biohorizon) was filled into the extraction socket to the crestal confines of the socket (Fig. 5). AlloDerm GBR (Biohorizon) was tacked over the socket bucally and lingually. Soft tissue was coronally advanced and 5-0 nylon (Ethicon) sutures were placed in (Fig. 6) Augmentin (Glaxosmithline) was prescribed as $675 \mathrm{mg}$ for 5 days. After 12 days the sutures were removed. Radiographic evaluation at 9 months presented as well-condensed bone (Fig. 7) and a thick keratinized soft tissue (Fig. 8). Ridge mapping revealed a midbuccal horizontal width and the soft tissue thickness as 6.1 and $2.3 \mathrm{~mm}$ respectively. Trephine bone core biopsy was done for histologic examination. Biohorizon $(4.2 \times 10 \mathrm{~mm})$ implant was placed in (Fig. 9). At 4 months, cover screw was removed and a $2 \mathrm{~mm}$ healing abutment was placed in (Fig. 10) 2 weeks later, impression was recorded for PFM prosthesis (Fig. 11). Owing to the reduced interocclual space, a screw retained prosthesis was seated in (Figs 12 and 13). The abutment screw was ratched at $35 \mathrm{Ncm}$ and the access hole was sealed. Histological examination under (H\&E, $\times 400)$ magnification revealed active bone formation in the areas adjacent to the graft material (Fig. 14).

\section{RESULTS}

Twenty-five months follow-up postrestoration revealed a stable prosthesis in function (Fig. 15).

\section{DISCUSSION}

Postextraction resorption rate is higher buccally than lingually. ${ }^{3}$ The loss of width of the alveolar ridge is always higher than the ridge height. ${ }^{4-7}$ Higher resorption has been reported in the maxilla than mandible. ${ }^{3}$ Socket augmentation helps to reduce the localized ridge deformities and help in a successful rehabilitation with endosseous implants. ${ }^{8}$ Research has shown that ridge bone maintenance procedures with the use of the biomaterials, helps in decreasing the expected bone loss and increases the success of rehabilitation 


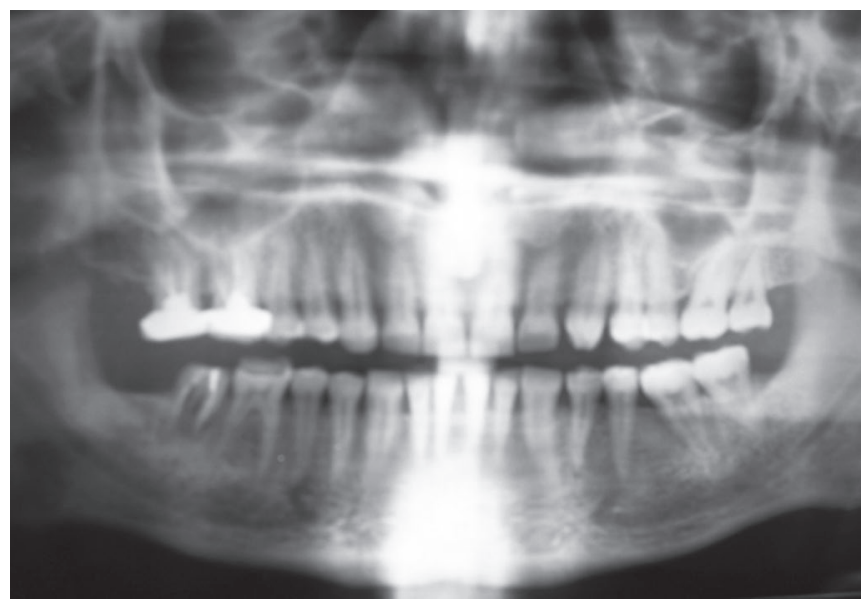

Fig. 1: Perio-endo lesion in relation to 47

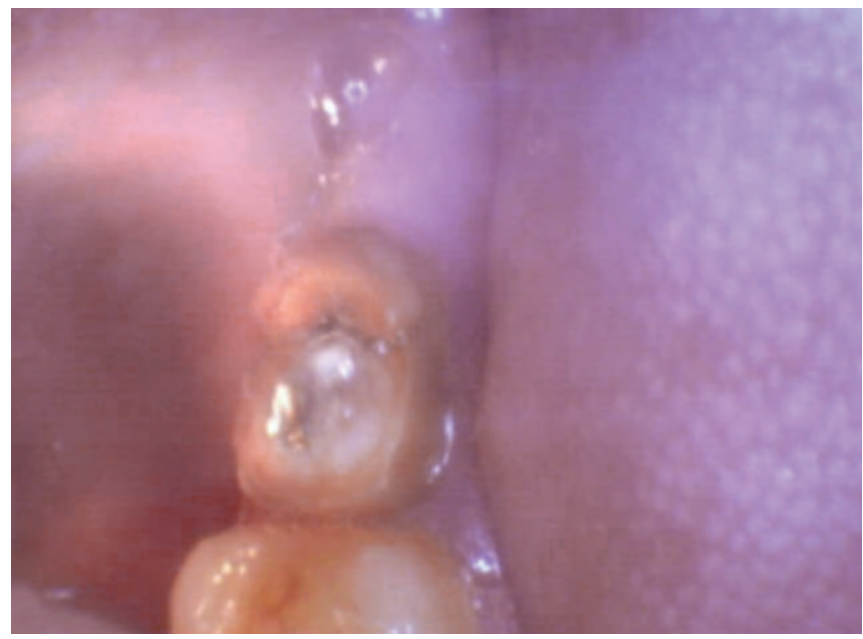

Fig. 3: Fractured 47

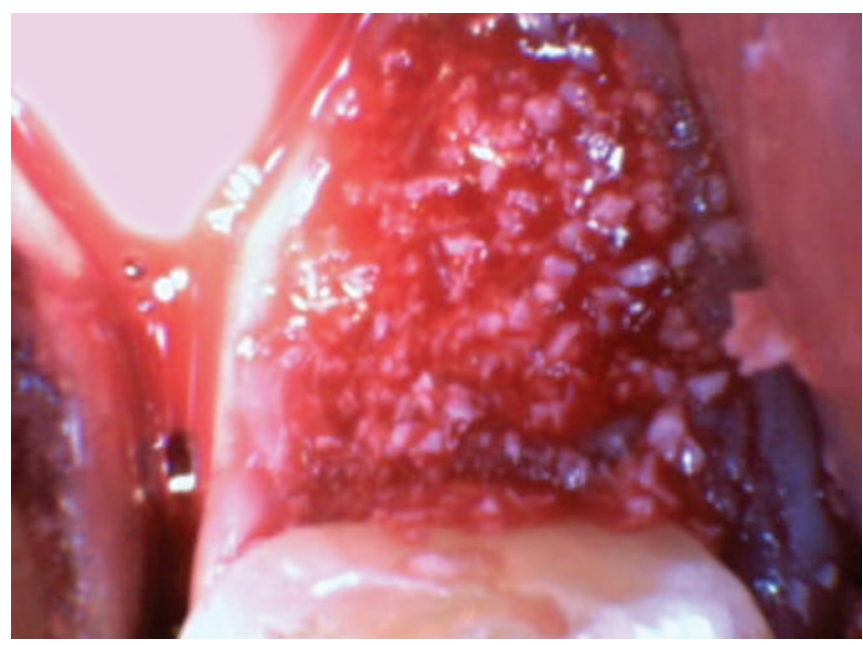

Fig. 5: MinerOss grafted into the extraction socket

after tooth extraction. ${ }^{9,10}$ Combination of bone grafts with other materials, e.g. PRP, GTR membranes, collagen plug, etc. were introduced to maximize the effect of the bone formation. In this case, we evaluate clinically, histologically

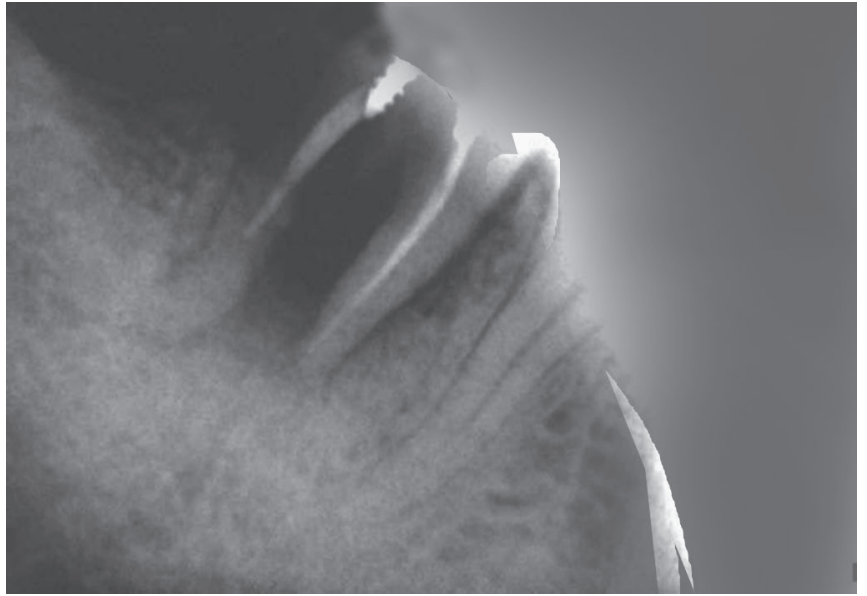

Fig. 2: Poor prognosis 47

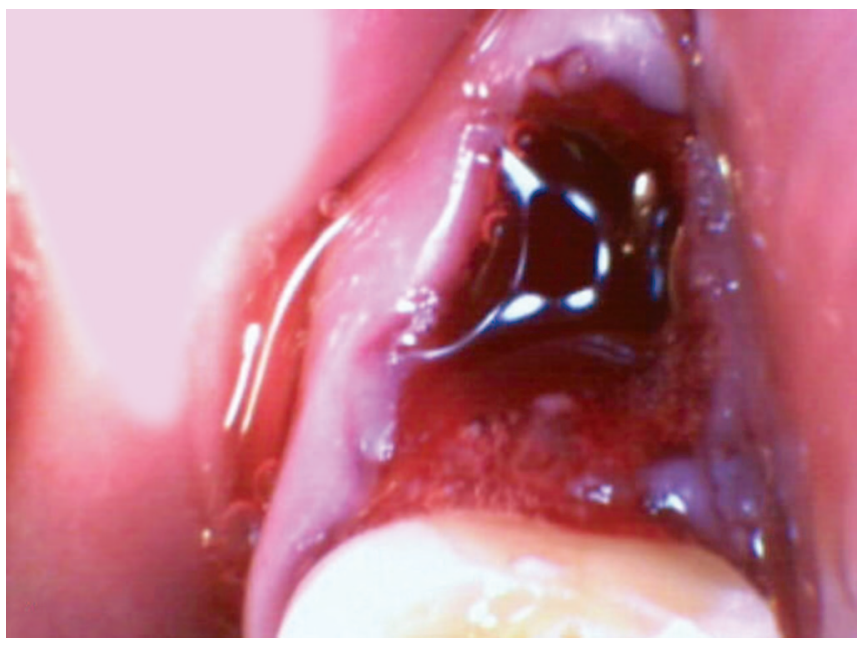

Fig. 4: Extraction socket

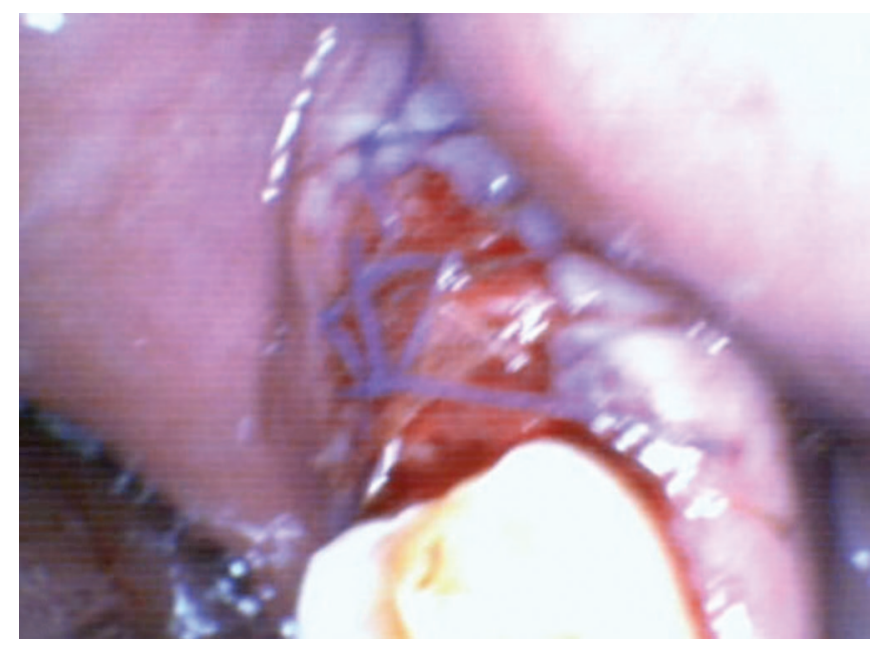

Fig. 6: AlloDerm tacked and suturing done

and radiographically the tissues formed around the implant in a socket presenting buccal bone defect utilizing the guided bone regeneration technique with corticocancellous graft and allograft GBR membrane. The GBR technique resulted in 


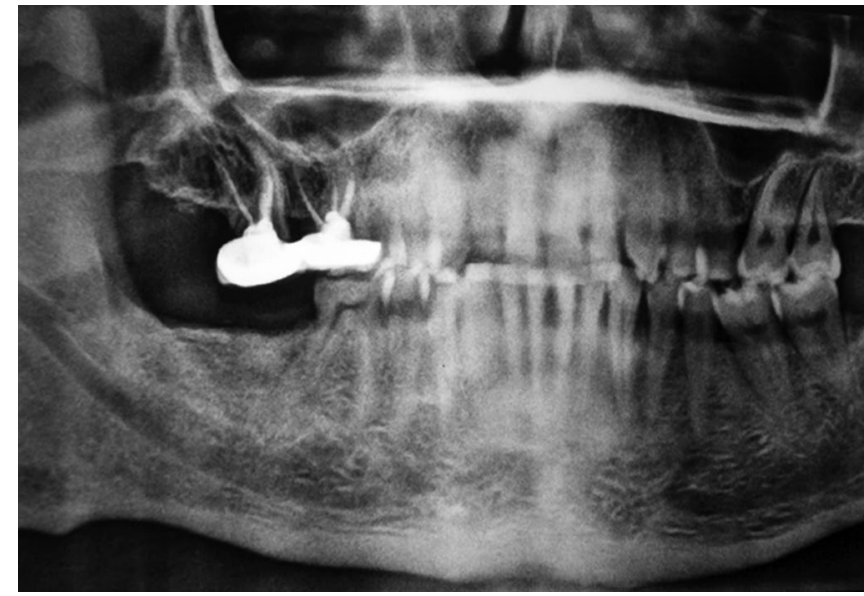

Fig. 7: Nine months postridge augmentation

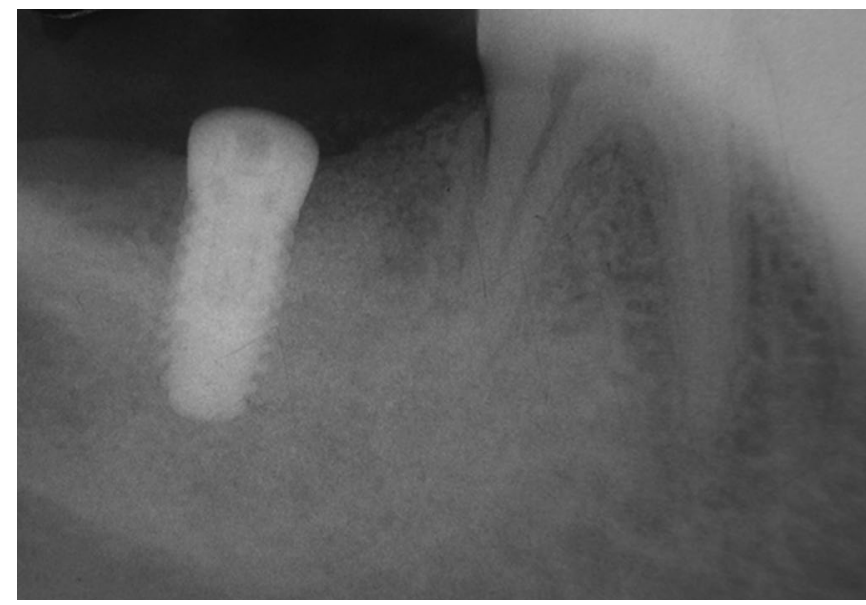

Fig. 9: Biohorizon $(4.2 \times 10 \mathrm{~mm})$ implant in place

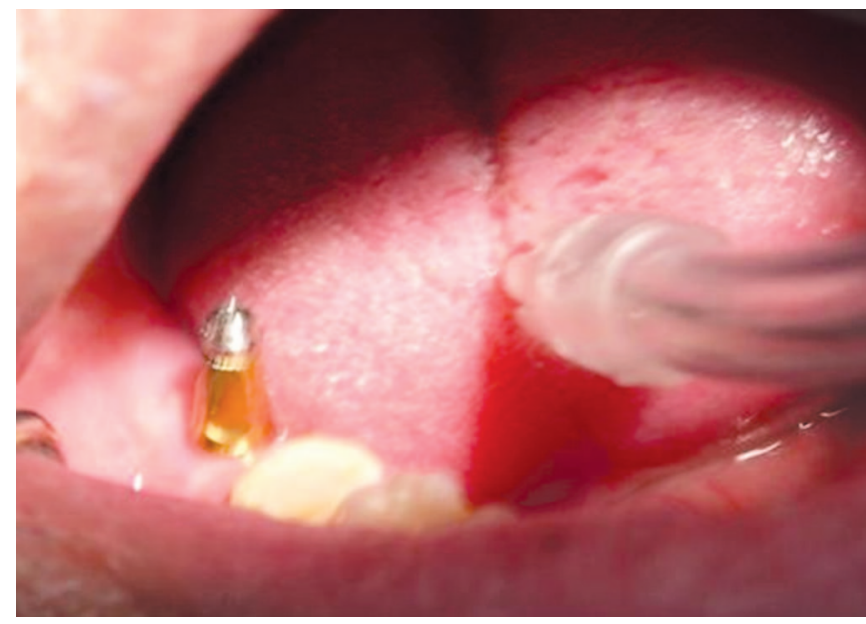

Fig. 11: Preparation for impression

$0.4 \mathrm{~mm}$ increase of horizontal width and a quantum bone fill around the implant. Appreciable keratinized mucosa resulted after healing. Histological section showed a viable bone formation in the vicinity of the bone graft with absence of any inflammatory cell findings.

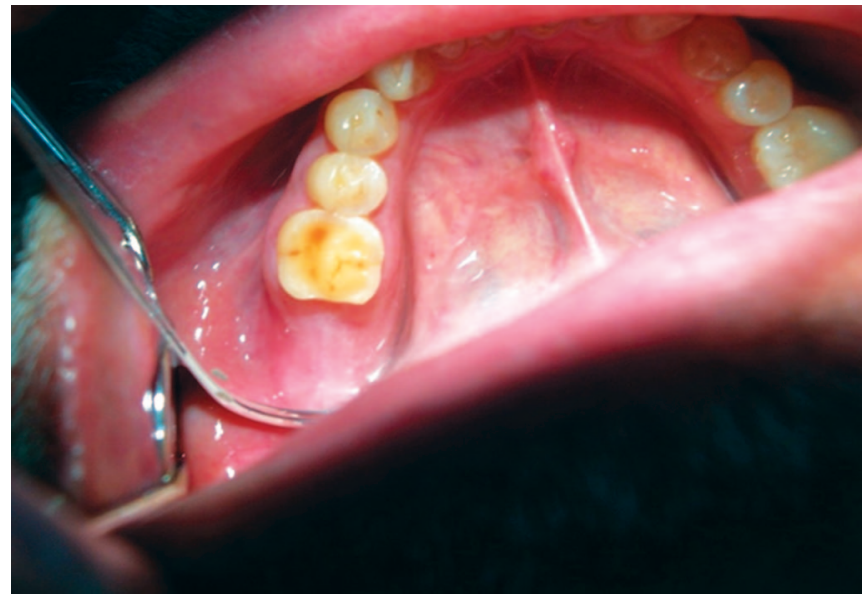

Fig. 8: Thick keratinized mucosa overlying the augmented site

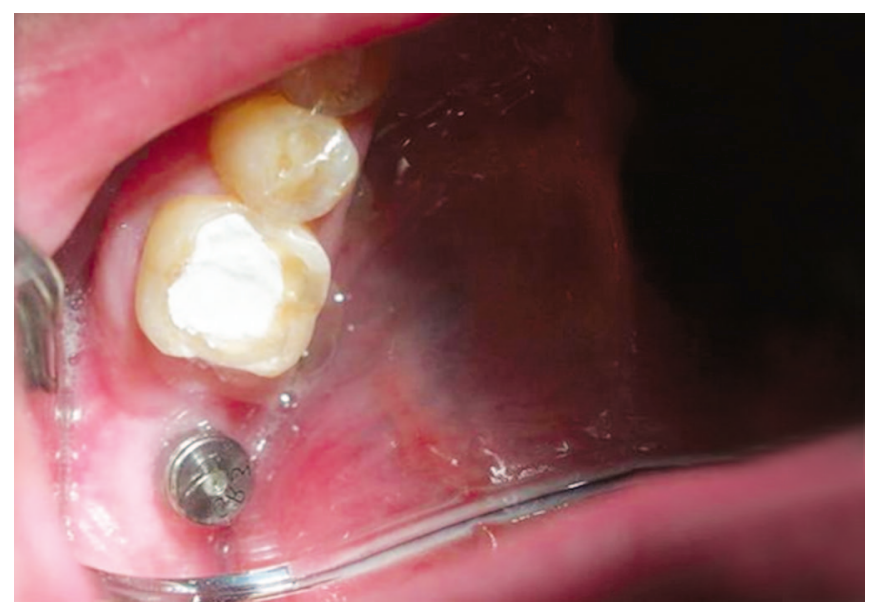

Fig. 10: Healing abutment in place

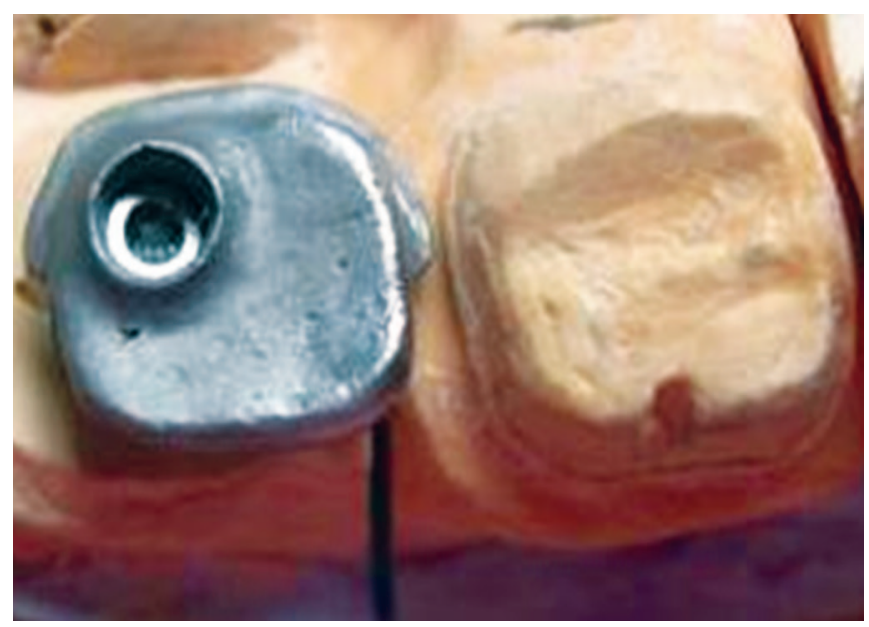

Fig. 12: Metal frame work for screw-retained prosthesis

\section{CONCLUSION}

The results from this case report indicates that ridge preservation is the ideal option to prepare the extraction site for future implant supported rehabilitation. 


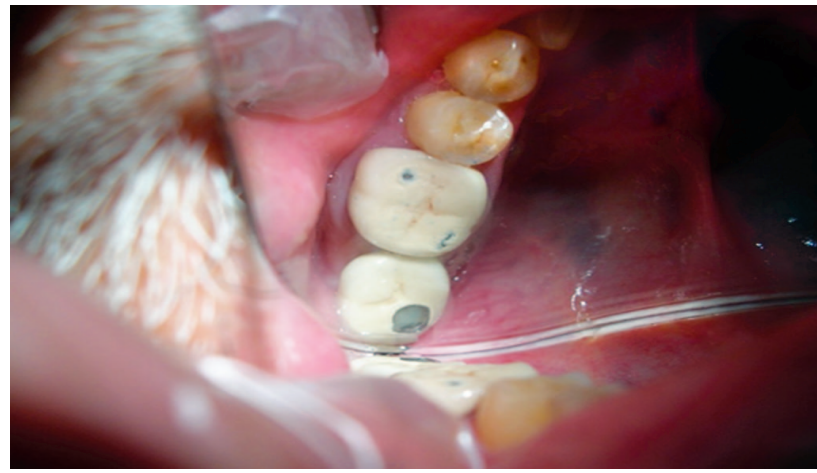

Fig. 13: Screw-retained prosthesis in place

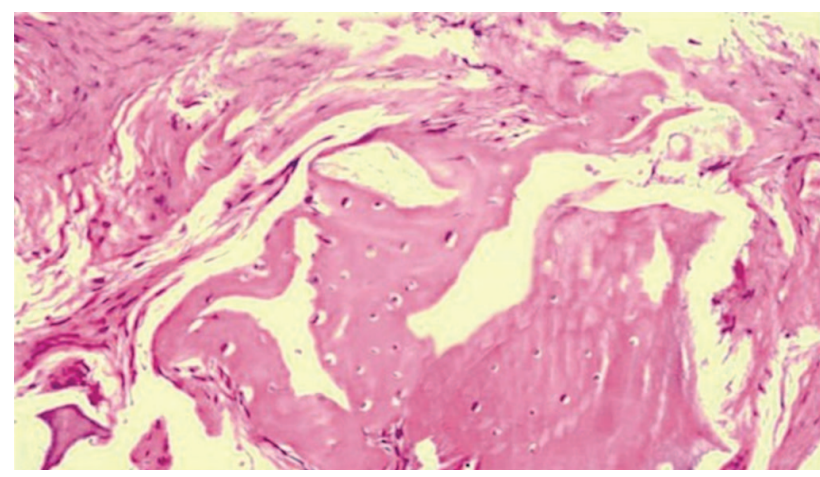

Fig. 14: Active bone formation adjacent to the resorbing graft particles $(H \& E, \times 400)$

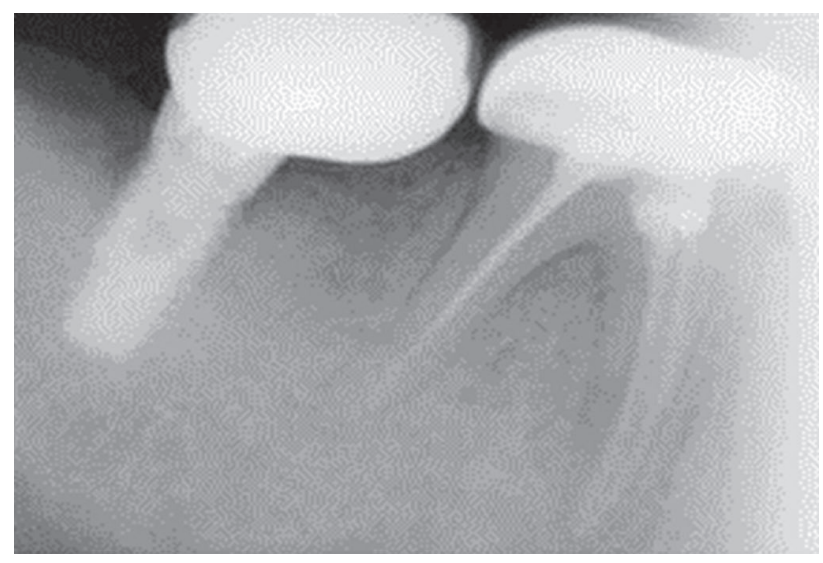

Fig. 15: Twenty-five months postrestoration

\section{REFERENCES}

1. Chen ST, Wilson TG. Immediate or ear implant placements following tooth extraction. Review of biologic basis, clinical procedures and outcomes. Int J Oral Maxillofac Implants 2004;19:12-25.

2. Schropp L, Wenzel A, Kostopoulus L. Bone healing and soft tissue contour changes following single tooth extraction: a radiographic and clinical 12 months retrospective study.

3. Pietrokovski J, Massler M. Alveolar ridge resorption following tooth extraction. J Prosth Dent 1967;17:21-27.

4. Lekovic V, Kenney EB, Weinlander M. A bone regenerative approach to alveolar ridge maintenance following tooth extraction. Report of 10 cases. J Periodontol 1997;68:563-570.

5. Lekovic B, Camargo PM, Klokkevold P. Preservation of alveolar bone in extarction socket using bioabsorbable membrane. J Periodontol 1998;69:1044-1049.

6. Johnson K. A study of the dimensional changes occurring in the maxilla following closed face immediate denture treatment. Aust Dent J 1969;14:371-376.

7. Johnson K. A study of dimensional changes occurring on the maxilla following tooth extraction. Aust Dent J 1969;14: 241-244.

8. Barboza EP. Localized ridge maintenance using bone membrane. Implant Dent 1999;8:167-172.

9. Bartee BK. Extraction site reconstruction for alveolar ridge preservation. Part 1: Rationale and materials selection. J Oral Impalntol 2001;27:187-193.

10. Becker W, Hujoel P, Becker BE. Effect of barrier membrane and autologous bone graft on ridge width preservation around implants. Clin Implant Dentist Related Res 2002;4:143-149.

\section{ABOUT THE AUTHORS}

\section{Sangeeta Dhir (Corresponding Author)}

Professor and Head, Department of Periodontology and Oral Implantology, Dr BR Ambedkar Institute of Dental Sciences, Patna Bihar, India, e-mail: sangeeta_dhir@hotmail.com

\section{Lanka Mahesh}

Private Practice, The Dental Centre, Panshila Park, New Delhi, India 